OPEN ACCESS

Edited by:

Maik Kurt Lang,

The University of Tennessee,

United States

Reviewed by:

Anna Shelyug,

Institute of Solid State Chemistry,

Russia

Wilson Crichton,

European Synchrotron Radiation

Facility, France

*Correspondence:

Gregory R. Lumpkin grl@ansto.gov.au

Specialty section:

This article was submitted to

Solid State Chemistry,

a section of the journal

Frontiers in Chemistry

Received: 16 September 2021

Accepted: 25 October 2021

Published: 12 November 2021

Citation:

Lumpkin GR and Aughterson RD (2021) Perspectives on Pyrochlores,

Defect Fluorites, and Related

Compounds: Building Blocks for Chemical Diversity and Functionality.

Front. Chem. 9:778140.

doi: 10.3389/fchem.2021.778140

\section{Perspectives on Pyrochlores, Defect Fluorites, and Related Compounds: Building Blocks for Chemical Diversity and Functionality}

\author{
Gregory R. Lumpkin * and Robert D. Aughterson \\ Australian Nuclear Science and Technology Organisation, Sydney, NSW, Australia
}

In this article we provide some perspectives on a range of pyrochlore and defect fluorite type compounds with nominal $\mathrm{A}_{2} \mathrm{~B}_{2} \mathrm{O}_{7}, \mathrm{~A}_{2} \mathrm{BO}_{5}, \mathrm{ABC}_{2} \mathrm{O}_{7}$, and other stoichiometries. Typically, the phase transformations and stability fields in these systems are mapped as a function of the ionic radii of the $\mathrm{A}$ and $\mathrm{B}$-site cations, e.g., the $\mathrm{A} / \mathrm{B}$ cation radius ratio $\left(r_{A} / r_{B}\right)$. This provides a useful guide to compatible structures and compositions for the development of advanced materials. Pyrochlore commonly transforms to a defect fluorite structure at high temperature in many systems; however, it is not uncommon to observe defect fluorite as the initial metastable phase at low temperature. The patterns of orderdisorder observed in these materials are primarily due to the energetics of layer stacking, the defect formation and migration energies of cations and anions, or modulations of the parent cubic structure in $3+n$ dimensional space. The first lead to predominantly noncubic derivatives of the parent defect fluorite structure (e.g., zirconolite polytypes), the second control the order-disorder processes, and the latter lead to a variety of subtle additional scattering features within the cubic parent structure. Although the energetics of cation disorder and anion-vacancy disorder have become more accessible via atomistic approaches (e.g., MD and DFT), we continue to find interesting physical-chemical problems in these materials. For example, although there are significant differences in composition ( $\mathrm{Tb} / \mathrm{Zr}$ ratio and $\mathrm{O}$ content) between $\mathrm{Tb}_{2} \mathrm{Zr}_{2} \mathrm{O}_{7}$ and $\mathrm{Tb}_{2} \mathrm{ZrO}_{5}$, both of which are defect fluorites, we note that the modulations found in these two compounds by electron scattering are virtually identical with regard to the direction and magnitude of displacement from the normal Bragg diffracted beams. This suggests that neither the A/B cation ratio nor the oxygen stoichiometry have a significant effect on the modulations. The general observations on the systems of compounds noted in this paper rest primarily in the context of industrial materials for nuclear waste disposal, potential applications in inert matrix fuel designs, and other important technological applications such as ionic conductivity, electrical conductivity, and magnetism. Scientific advances in these areas have been underpinned by recent advances in ion irradiation, synchrotron X-ray, neutron scattering, and modelling and simulation capabilities. Furthermore, there has been some renewed interest in natural samples, e.g., Th-U zirconolite and pyrochlore as analogues for potential host phases in nuclear waste forms. In particular, the natural pyrochlores have provided additional details with regard to radiation damage ingrowth, percolation 
transitions, and the relationships between accumulated dose and physical properties including hardness, elastic modulus. Specific details of the thermal annealing of these samples have also been elucidated in considerable detail.

\section{Keywords: defect fluorite, modulated structures, pyrochlore, weberite, zirconolite}

\section{INTRODUCTION}

Compounds based on the structure of fluorite, including pyrochlore, zirconolite, and related structure types with different stoichiometries (Table 1) are of interest for numerous technological applications, including nuclear fuel and related materials (e.g., inert matrix fuel), nuclear waste forms, fast ion conductors, and magnetic materials, among others. Starting with the basic fluorite structure, ${ }^{\mathrm{VIII}} \mathrm{M}^{\mathrm{IV}} \mathrm{X}_{2}$, where $\mathrm{M}$ can be a range of medium to large tetravalent cations (e.g., $\mathrm{Zr}, \mathrm{Hf}, \mathrm{Th}, \mathrm{U}$ ) or divalent cations (e.g., Ca, Sr, $\mathrm{Ba}$ ) in eightfold coordination and $\mathrm{X}$ is typically $\mathrm{O}^{2-}$ or $\mathrm{F}^{-}$in fourfold coordination, there are many variations on the theme when considering charge balancing combinations of cations and anions. A major outcome of the crystal chemical flexibility of the fluorite structure type is the ability to incorporate monovalent and trivalent cations, in particular $\mathrm{Y}$ and rare earth elements, presenting a wealth of compositions and potentially useful properties. These structures exist in cubic space group $\mathrm{Fm} 3 \mathrm{~m}$ and when there is more than one cation present, they are generally disordered over the available cation sites; however, in many compositions electron diffraction patterns reveal the structures also include one or more modulations of the parent fluorite structure (Withers et al., 1991; Tabira et al., 2001). These modulated structures indicate the presence of chemical and/or displacive disorder within the underlying crystal structure. Furthermore, oxygen vacancies may be present if additional cations having lower valence states (e.g., $\mathrm{Y}^{3+}$ or $\mathrm{Ca}^{2+}$ ) are not charge balanced by higher valence cations (e.g., $\mathrm{W}^{6+}$ or $\mathrm{Nb}^{5+}$ ) with the cations, anions, and vacancies being disordered over the available lattice sites. These compounds are commonly referred to as defect fluorites.
Ordered derivatives of the defect fluorite structure include compounds with the $\mathrm{A}_{2} \mathrm{~B}_{2} \mathrm{O}_{7}$ pyrochlore structure ("227" type, e.g., Subramanian et al., 1983; Chakoumakos 1984), the weberite group of layered compounds, consisting of "227" and "317" type compositions depending on valence states of the cations (Cai and Nino, 2009; Euchner et al., 2019), the $\mathrm{A}_{3} \mathrm{BO}_{7}$ defect fluorite structures ("317" type), and the $\mathrm{A}_{2} \mathrm{BO}_{5}$ ("215" type) compounds described by Lau et al. (2007); Shepelev and Petrova (2008); Lau et al. (2008); Aughterson et al., 2014; Aughterson et al., 2015; Aughterson et al., 2018b. Furthermore, the zirconolite structure types with the general formula $\mathrm{ABC}_{2} \mathrm{O}_{7}$ encompass a smaller group of layered compounds with non-cubic symmetry but based on a defect fluorite subcell. These compounds have useful properties including the ability to incorporate actinides, extreme chemical flexibility across three types of crystallographic sites, and very high resistance to dissolution. Together with pyrochlore, a range of zirconolite compositions have been developed and extensively tested as a major component of nuclear waste forms (e.g., Vance et al., 2002; Strachan et al., 2005, Strachan et al., 2008; Icenhower, et al., 2006). In these broad families there are numerous compounds that are known and possibly others yet to be synthesized in the laboratory, providing a fertile ground for continued discovery research in phase transitions and useful industrial properties. The high level of interest in these materials has been evidenced by numerous papers in the scientific literature. Many of these compounds already have important technological applications in areas including nuclear fuel, nuclear waste forms, fast ion conductors, magnetism, and other areas of materials science (Subramanian et al., 1983; van Dijk et al., 1983; Kutty et al., 1994; Wang et al., 1999; Risovany et al., 2000; Vassen et al., 2000; Wu et al., 2002; Lutique et al.,

TABLE 1 | Some general aspects of ordered structure types and their related disordered, defect fluorite structures. Table is arranged by increasing $M / X$ ratio from top to bottom.

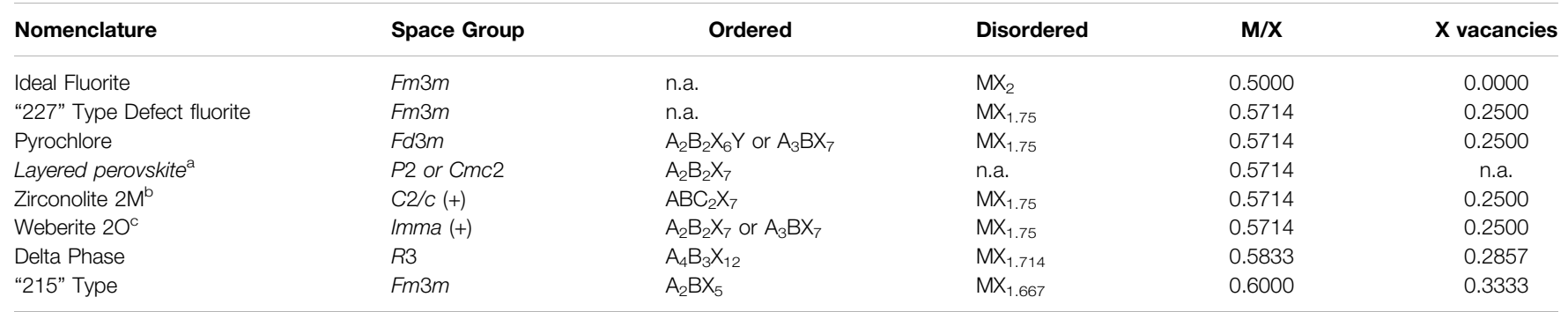

${ }^{a}$ These compounds are not defect fluorites, but they do consist of perovskite layers alternating with $\mathrm{A}_{2} \mathrm{O}_{3}$ layers which have some topological resemblance to the fluorite structure. They are included for reference due to possible phase transitions to pyrochlore, etc.

${ }^{b}$ Plus numerous polytypes and space groups due to layer stacking variations, including $3 T, 30.4 \mathrm{M}$, and 6T. In general, layered structures may be complicated by the intergrowth of polytypes and/or stacking disorder. Incommensurate, modulated structures may be observed in the defect fluorite compounds, including 227 type, 317 type, delta phase, and 215 type compounds as a function of composition and overall stoichiometry. The $X$ anion vacancies are given relative to the ideal fluorite structure.

${ }^{c}$ Plus numerous polytypes and space groups due to layer stacking variations, including $20,2 \mathrm{M}, 3 \mathrm{~T}, 4 \mathrm{M}, 5 \mathrm{M}, 6 \mathrm{M}, 6 \mathrm{~T}, 7 \mathrm{M}$, and 80 . 
2003a; Lutique et al., 2003b; Shlyahktina et al., 2005; Bansal and Zhu, 2007; Shimamura et al., 2007; Radhakrishnan et al., 2011; Sattonnay et al., 2013; Maram et al., 2018; Euchner et al., 2019; Lyashenko et al., 2010).

\section{STRUCTURE TYPES}

Several groups of ordered fluorite-related compounds are compared in Table 1 together with their alternative disordered formulations. The defect fluorite structure type is based upon the classical fluorite structure $(\mathrm{Fm} 3 m)$ with $\mathrm{M}^{\mathrm{VIII}} \mathrm{X}_{2}^{\mathrm{IV}}$ stoichiometry wherein the Roman number superscripts refer to the coordination numbers of the cations and anions, respectively. In general, $\mathrm{M}$ is typically $\mathrm{Ca}, \mathrm{Sr}, \mathrm{Ba}$, and $\mathrm{Pb}$ for the compounds with $\mathrm{X}=\mathrm{F}$ or $\mathrm{Zr}, \mathrm{Hf}$, Th, $\mathrm{U}, \mathrm{Pu}$, and $\mathrm{Cm}$ when $\mathrm{X}=\mathrm{O}$. However, in order to accommodate cations of lower or higher than the average 4 + valence state, the actual compositions may be oxygen deficient or in excess and the general formula can be written as $\mathrm{MX}_{2 \pm \mathrm{x}}$. For oxides, this formula is consistent with charge compensation by fewer oxygen anions if the average cation valence state is less than 4.0 , leading to anion vacancies in the structure and a reduction of the cation-anion coordination number. This is the typical situation for the compounds often referred to as defect fluorites. However, if the average valence state is greater than 4.0, then excess oxygen may be present, up to some stability limit. Most nuclear fuels are based on $\mathrm{UO}_{2}+\mathrm{x}$ wherein $\mathrm{U}^{4+}$ is the nominal starting valence state, but higher valence states $\left(\mathrm{U}^{5+}\right.$ and/ or $\mathrm{U}^{6+}$ ) may occur in spent fuel under oxidizing conditions, leading to the condition where $\mathrm{x}>2$. In Table 1 we list some of the structure types of interest by increasing $\mathrm{M} / \mathrm{X}$ ratio from ideal fluorite $(\mathrm{M} / \mathrm{X}=0.5)$ to the " 215 " type compounds $(\mathrm{M} / \mathrm{X}=0.6)$. This also relates to an increasing number of $\mathrm{X}$ anion vacancies in the defect fluorite asymmetric unit, which may be relevant to some of the properties (e.g., ionic transport, radiation tolerance, etc.) of the different compounds.

Ordered oxide pyrochlores are described by the general formula $\mathrm{A}_{2} \mathrm{~B}_{2} \mathrm{X}_{6} \mathrm{Y}$ (after Chakoumakos, 1984) which can be expanded to reveal the coordination environments and vacant sites in space group $F d 3 m$ relative to the underlying disordered $\mathrm{MX}_{2}$ fluorite basis in space group $\mathrm{Fm} 3 \mathrm{~m}$. The ordered oxide pyrochlore form can be expressed as: ${ }^{\mathrm{VIII}} \mathrm{A}_{2}{ }^{\mathrm{VI}} \mathrm{B}_{2}{ }^{\mathrm{IV}} \mathrm{X}_{6}{ }^{\mathrm{IV}} \mathrm{Y}$, where the Roman numerals represent the coordination numbers of the $\mathrm{A}$ and $\mathrm{B}$ cations, and the $\mathrm{X}$ and $\mathrm{Y}$ anions. In pyrochlore, the $A$ and $B$ cations are both on fixed positions located at $16 d$ and $16 c$, with the $\mathrm{X}$ anions located on $48 f$ and the $\mathrm{Y}$ anions located on $8 b$. We note that natural pyrochlores are common in evolved igneous systems, e.g., carbonatites and granitic pegmatites. The minerals are typically described by the end members $\quad \mathrm{NaCaNb}_{2} \mathrm{O}_{6} \mathrm{~F} \quad$ (pyrochlore), $\quad \mathrm{NaCaTa}_{2} \mathrm{O}_{6} \mathrm{~F}$ (microlite), $\mathrm{CaUTi}_{2} \mathrm{O}_{7}$ (betafite), and other "end-member" components such as $\mathrm{Ln}_{2} \mathrm{Ti}_{2} \mathrm{O}_{7}$ ( $\mathrm{Ln}=$ lanthanides). Pyrochlore may be considered the quintessential "227-type" oxide compound and there are literally hundreds of compounds, both natural and synthetic, that exist in this structural configuration. Subramanian et al. (1983) provided one of the earliest comprehensive reviews of pyrochlore with extended discussion of potentially useful properties, including magnetism, electrical properties, and oxygen ion migration.

The structure of zirconolite can be thought of as a pyrochlore that is compressed normal to one set of (111) planes, resulting in a layered structure in the prototype space group $C 2 / c$ which refers to a 2-layered structure. Nevertheless, this structure retains evidence of the cubic defect fluorite subcell and may transform from monoclinic to cubic symmetry under irradiation during a crystalline to amorphous phase transformation. The composition of zirconolite is generally described by the general formula $\mathrm{ABC}_{2} \mathrm{O}_{7}$ wherein $\mathrm{A}=\mathrm{Ca}$, larger actinide and lanthanide cations, $\mathrm{B}=\mathrm{Zr}$, Ti, and smaller actinide and lanthanide cations, and $\mathrm{C}=\mathrm{Ti}, \mathrm{Zr}, \mathrm{Hf}, \mathrm{Nb}, \mathrm{Ta}, \mathrm{Al}$, $\mathrm{Mg}$, and transition metals. Various polytypes of zirconolite will form due to layer stacking sequences as a function of composition, including structures based on 3, 4, and 6-layer structural configurations.

The prototype for the weberite structure is orthorhombic, in space group Imma, has the 227-type stoichiometry, and the name was originally given to a mineral having the composition $\mathrm{Na}_{2} \mathrm{MgAlF}_{7}$ (Knop et al., 1982). As indicated in Table 1, the weberite structure is also adopted by some compounds with $317-$ type stoichiometry. For the compounds $\mathrm{Y}_{3} \mathrm{TaO}_{7}$, Gussev et al. (2020) noted that the space group of the long-range structure is consistent with either of two space groups, $\mathrm{Ccmm}$ or $\mathrm{C} 222_{1}$, but using neutron pair distribution function (pdf) analysis, they demonstrated that the short-range structure in best represented in the latter space group. The crystal structure is derived from fluorite and is similar to the pyrochlore structure. The two structures have a similar cation sublattice with A cations in 8-fold coordination and $\mathrm{B}$ cations in six-fold coordination and built around (111) layers having the hexagonal tungsten bronze topology. As summarized by Cai and Nino (2009), there exists broad compositional flexibility in the weberite structure in both fluoride and oxide compounds. In oxide weberites, the A-sites are typically occupied by $\mathrm{Na}, \mathrm{K}, \mathrm{Ag}, \mathrm{Ca}, \mathrm{Mn}, \mathrm{Cd}, \mathrm{Sr}, \mathrm{Ba}, \mathrm{Y}$, and lanthanides, whereas the $\mathrm{B}$-sites are home to $\mathrm{V}, \mathrm{Sb}, \mathrm{Te}, \mathrm{Nb}, \mathrm{Ta}$, $\mathrm{Os}, \mathrm{Bi}$, and $\mathrm{U}$. In the latter two cases, the weberite compounds are $\mathrm{Sr}_{2} \mathrm{Bi}_{2} \mathrm{O}_{7}$ and $\mathrm{Ba}_{2} \mathrm{U}_{2} \mathrm{O}_{7}$ in which the $\mathrm{B}$-site cations must be hexavalent by charge balance $\left(\mathrm{Bi}^{6+}\right.$ and $\left.\mathrm{U}^{6+}\right)$ unless there are oxygen vacancies in the structure.

The delta phase refers to another group of lanthanide metal oxide compounds with rhombohedral symmetry (space group R3) and related to defect fluorite structures when disordered. These compounds are based on the general formula $\mathrm{A}_{4} \mathrm{~B}_{3} \mathrm{O}_{12}$ wherein $\mathrm{A}=$ trivalent cations (e.g., $\mathrm{Sc}, \mathrm{Y}$ and lanthanides) and $\mathrm{B}=$ tetravalent cations, primarily synthesized with $\mathrm{B}=\mathrm{Zr}$ at this point in time. The composition of the delta phase can be reformulated to a pyrochlore type formula as: ${ }^{\mathrm{VIII}} \mathrm{A}_{2}{ }^{\mathrm{VI}}\left(\mathrm{A}_{0.286} \mathrm{~B}_{1.714}\right)$ ${ }^{\mathrm{IV}} \mathrm{O}_{6}{ }^{\mathrm{IV}} \mathrm{O}_{0.857}$, and this equates to $\mathrm{MX}_{1.714}$ if represented as a disordered, defect fluorite structure. Compounds with the delta phase structure and stoichiometry are commonly encountered as intermediate compositions in some of the A-B metal oxide systems that have been studied to date.

Considerable recent interest in the $\mathrm{A}_{2} \mathrm{BO}_{5}$ or " 215 " structure types has been generated from studies of the phase relations for systems with $\mathrm{A}=\mathrm{Y}$ and lanthanides and $\mathrm{B}=\mathrm{Ti}$ (e.g., Shepelev and 
A

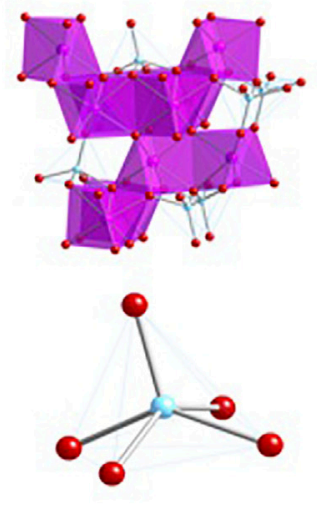

B

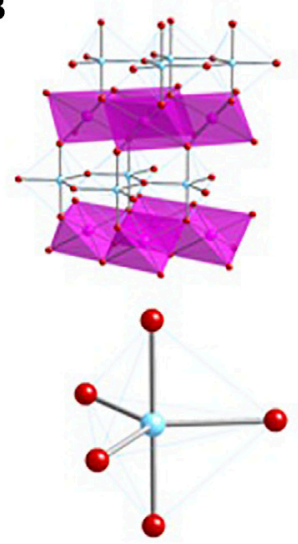

C
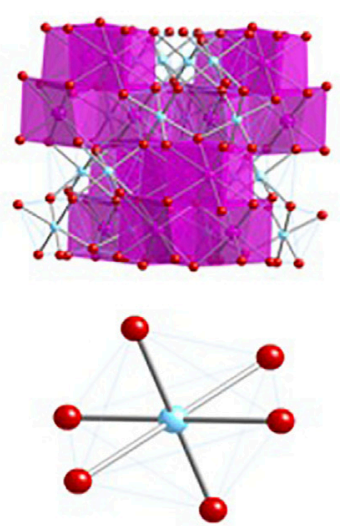

D
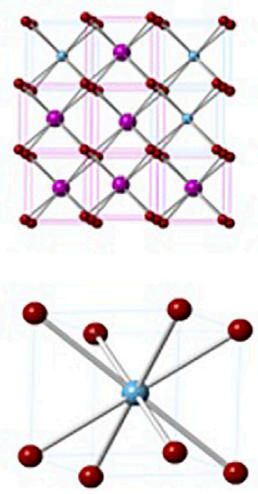

FIGURE 1 | Crystal structures of the $\mathrm{A}_{2} \mathrm{BO}_{5}$ compounds with $\mathrm{B}=\mathrm{Ti}$. (A) Orthorhombic structure. (B) Hexagonal structure. (C) Cubic, pyrochlore-like structure. (D) Cubic defect fluorite structure. Note that the cubic form of $\mathrm{Dy}_{2} \mathrm{TiO}_{5}$ may not be fully resolved as of mid-2021. The cubic form of $\mathrm{Ho}_{2} \mathrm{TiO}_{5}$ and $\mathrm{Y}_{2} \mathrm{TiO}_{5}$ consists of a pyrochlore-like structure with a 3x superstructure on (111) planes and a 7x repeat on (622) planes, as described previously (Shepelev and Petrova, 2006, Lau et al., 2007; Lau et al., 2008; Shepelev and Petrova, 2008; Aughterson et al., 2014, Aughterson et al., 2015, Aughterson et al., 2018b).

Petrova, 2006, 2008). When the A-site cation is Ho or other cations of similar radius, notably $\mathrm{Y}$, or other cations from Dy to Er, a pyrochlore-like cubic structure forms with the nominal space group Fd3m (Lau et al., 2007, Lau et al., 2008; Aughterson et al., 2014). Although similar to the ordered structure of the $\mathrm{A}_{2} \mathrm{~B}_{2} \mathrm{X}_{6} \mathrm{Y}$ pyrochlores, the pyrochlore-like $\mathrm{A}_{2} \mathrm{BO}_{5}$ structure is more complicated and as demonstrated using electron microscopy, the structure shows a tripling of along [111] directions and a less obvious, sevenfold repeat along the [622] directions when viewed down (110) in electron diffraction patterns. This incorporation of smaller lanthanide cations on the A-site leads to a transformation from the tripled pyrochlore structure to a disordered defect fluorite structure in these compounds.

In comparison to the " 227 " pyrochlores, following Newman et al. (2018) the "215" type cubic compounds can be reformulated from $\mathrm{A}_{2} \mathrm{BO}_{5}$ to give ${ }^{\mathrm{VIII}} \mathrm{A}_{2}{ }^{\mathrm{VI}}\left(\mathrm{A}_{0.667} \mathrm{~B}_{1.333}\right)^{\mathrm{IV}} \mathrm{O}_{6}{ }^{\mathrm{IV}} \mathrm{O}_{0.667}$, in which $\mathrm{A}$ and $\mathrm{B}$ are trivalent and tetravalent cations, respectively. This expression is particularly applicable to the $\mathrm{A}_{2} \mathrm{BO}_{5}$ compounds that are related to pyrochlore. As shown in Figure 1, the 215-type compounds adopt orthorhombic, hexagonal, and cubic structures from $\mathrm{A}=\mathrm{La}$ to $\mathrm{Lu}$ and $\mathrm{B}=\mathrm{Ti}$. In samples with $\mathrm{B}=\mathrm{Ti}$ and $\mathrm{A}=\mathrm{Y}$ or Ho, the $A / / B$ ratio of $2 / 1$ leads to a pyrochlore-like structure which exhibits a tripling of the lattice repeat distance on (111) planes, a feature that is not present in samples with other A-site cations or in any of the known compounds with $\mathrm{B}=\mathrm{Zr}$. The tripled lattice repeat may be due to a partial ordering of the A and $\mathrm{B}$ cations in the structure. We note, however, that electron diffraction patterns taken in the [110] zone axis orientation also show evidence of a 7 -fold repeat on the (662) planes, as first described by Lau et al. (2007). This structure evolves to a disordered, defect fluorite with incorporation of progressively smaller cations from Er to Lu. On disordering of the cations and anions, the formula ${ }^{\mathrm{VIII}} \mathrm{M}^{\mathrm{IV}} \mathrm{X}_{2-\mathrm{x}}$ reflects the local coordination environments of the structure in space group $\mathrm{Fm} 3 \mathrm{~m}$ with the anion deficiency determined by the average valence state of the cations, giving $\mathrm{x}=0.25$ and 1.75 total oxygens in the formula for the 227 type pyrochlore $(\mathrm{M} / \mathrm{X}=0.5714)$ and $\mathrm{x}=0.333$ and 1.667 total oxygens in the formula for the 215 type $(\mathrm{M} / \mathrm{X}=0.6000)$. In the disordered defect fluorite structure, the formulae for 227 and 215 type compounds are $\mathrm{MX}_{1.75}$ and $\mathrm{MX}_{1.667}$, respectively.

\section{PHASE TRANSITIONS}

In setting the stage for the work to be presented here, it is important to proceed with a fundamental understanding of the pyrochlore to defect fluorite phase transformation and the underlying physical chemistry in relation to changes in stoichiometry as evidenced by intrinsic properties such as the $\mathrm{A} / \mathrm{B}$ cation ionic radii and numerical ratios and overall cation/ anion ratios in these materials. Extrinsic properties-time, temperature, and pressure also have an influence on the phase transformation. For example, during synthesis $\mathrm{Gd}_{2} \mathrm{Zr}_{2} \mathrm{O}_{7}$ initially crystallizes in the defect fluorite form, possibly as a metastable phase built on a nano-domain model recently proposed by Simeone et al. (2017), but then transforms to an ordered pyrochlore at $\sim 1,250-1,300^{\circ} \mathrm{C}$. At higher temperatures up to $\sim 1,500^{\circ} \mathrm{C}$ the structure transforms back to the disordered defect fluorite structure (see, e.g., Zhou et al., 2016 and references therein), so in many of these refractory oxide systems it is not uncommon for the thermodynamically stable lower temperature form to be kinetically inhibited during the chemical synthesis and thermal processing stage. Even at high temperature, the reaction rates in these systems may be slow, meaning that assessments of equilibrium should be approached with caution.

As a result of interest in host phases for actinides and fission products in nuclear waste forms, some of the phase transitions from the $\mathrm{ABC}_{2} \mathrm{X}_{7}$ zirconolite compounds to $\mathrm{A}_{2} \mathrm{~B}_{2} \mathrm{O}_{7}$ pyrochlore have been studied in considerable detail. However, these studies have mostly been conducted on ceramic samples as a function of composition with limited temperature variation. Vance et al. 

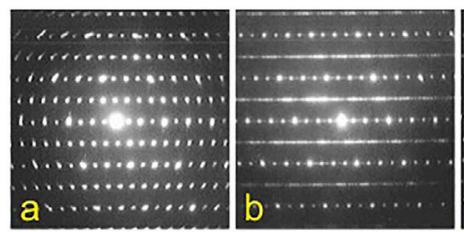

$2 \mathrm{M}$

$2 M+4 M$

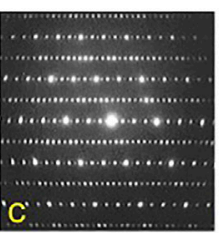

$4 \mathrm{M}$

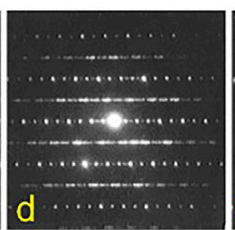

$4 M+P y$

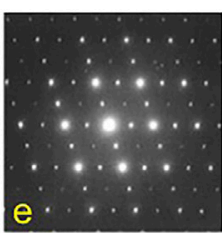

Py

Uranium content in ceramic

Alpha decay per unit time

Dissolution rate at time (t)

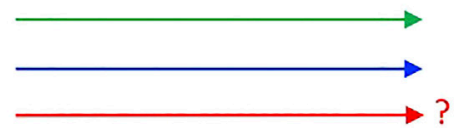

FIGURE 2 | Phase transformations in the series $\mathrm{CaZrTi}_{2} \mathrm{O}_{7}-\mathrm{CaUTi}_{2} \mathrm{O}_{7}$ from zirconolite to pyrochlore. From left to right, there are two main zirconolite polytypes $(2$ and $4 \mathbf{M}$ ), three single-phase fields (A, C, E), and two intervening two-phase fields (B, D) in this system. Similar materials have served as the basis for nuclear waste forms for Pu and other actinides, with reasonably high resistance to aqueous dissolution and release of radioactive components. Adapted from Vance et al. (2002).
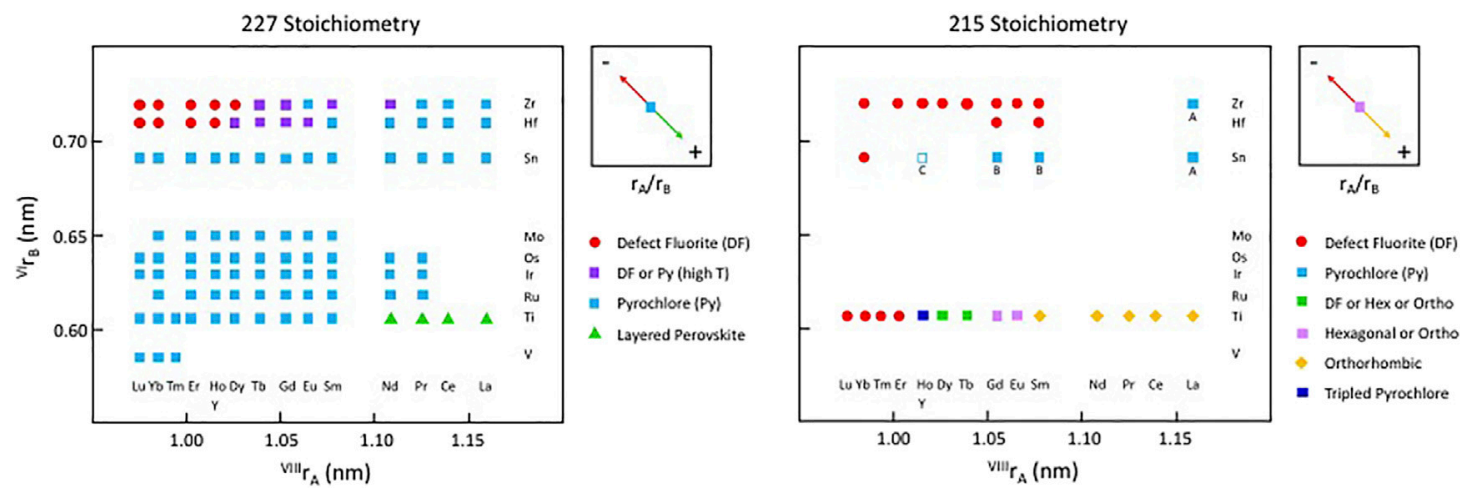

FIGURE 3 | Structure-field map for the $\mathrm{A}_{2} \mathrm{~B}_{2} \mathrm{O}_{7}$ system on the left and a partial structure-field map for some of the known $\mathrm{A}_{2} \mathrm{BO}_{5}$ compounds on the right, both with $\mathrm{A}=$ lanthanides and $\mathrm{Y}$ and $\mathrm{B}=$ selected transition metals at low pressure. This figure does not include the weberite type layered compounds with "227" stoichiometry. Only the series with $\mathrm{B}=\mathrm{Ti}, \mathrm{Sn}, \mathrm{Hf}$, or $\mathrm{Zr}$ have been studied fully across the range of $\mathrm{A}$-site constituents and for solid-solutions between both $\mathrm{A}$-site and $\mathrm{B}$-site constituents. The compound $\mathrm{Y}_{2} \mathrm{SnO}_{5}$, is shown with an open square as this may be A-site deficient and multiphase, containing $\mathrm{C}$-type $\mathrm{Y}_{2} \mathrm{O}_{3}$. Other compounds with $\mathrm{A}=\mathrm{Gd}$ and $\mathrm{Sm}$ and $\mathrm{B}=\mathrm{Sn}$ may contain $\mathrm{B}$-type $\mathrm{Gd}_{2} \mathrm{O}_{3}$ and $\mathrm{Sm}_{2} \mathrm{O}_{3}$, whereas compounds with $\mathrm{A}=\mathrm{La}$ and $\mathrm{B}=\mathrm{Sn}$ and $\mathrm{Zr}$ may contain the $\mathrm{A}$-type $\mathrm{La} \mathrm{O}_{3} \mathrm{O}_{3}$ compound as an extra phase (indicated by the letters $\mathrm{A}, \mathrm{B}$, or $\mathrm{C}$ below the symbols). These latter details remain to be investigated.

(2002) conducted an important study of the incorporation of uranium in zirconolite which built some of the foundations for subsequent nuclear waste form development. This work showed that substitution of $\mathrm{U}$ in zirconolite from $\mathrm{CaZrTi}_{2} \mathrm{O}_{7}$ to $\mathrm{CaUTi}_{2} \mathrm{O}_{7}$ resulted in the following phase fields: zirconolite $2 \mathrm{M}$, zirconolite $2 \mathrm{M}+4 \mathrm{M}$, zirconolite $4 \mathrm{M}$, zirconolite $4 \mathrm{M}+$ pyrochlore, and pyrochlore, as shown in Figure 2. The ability to produce ceramics in this system with fluorite superstructures, high aqueous durability, and considerable compositional flexibility led to the successful development of similar nuclear waste forms for $\mathrm{Pu}$ remediation (see Strachan et al., 2005; Icenhower et al., 2006; Strachan et al., 2008). In fact, this system can be tailored for the best balance of waste loading, additives (e.g., neutron absorbers), fission products, an overall aqueous durability (see Lumpkin, 2006, for further discussion and an example of a Pu-based pyrochlore-zirconolite waste form).

Figure 3 shows a version of the well-known structure map for the 227 type compounds with $\mathrm{A}=$ trivalent $\mathrm{Y}$ or $\mathrm{La}-\mathrm{Lu}$ and $\mathrm{B}=$ tetravalent V, Ti, Ru, Ir, Os, Mo, Sn, Hf, and Zr. This structurefield map reveals that the titanates with La-Nd prefer the monoclinic layered perovskite structure (e.g., Harvey et al., 2004 and references therein) whereas the hafnates and zirconates with Lu-Y/Ho prefer the cubic, defect fluorite (DF) structure. This structure is the classical defect fluorite based on space group $F m 3 m$ with cations and anions disordered over the available sites. In between these two-phase fields, we find that most of the compounds in this system adopt the ordered pyrochlore $(\mathrm{Py})$ structure and that a few of the hafnates $(\mathrm{A}=$ Dy-Eu) and zirconates $(\mathrm{A}=\mathrm{Tb}-\mathrm{Nd}$, not including $\mathrm{Eu})$ can be transformed to the disordered defect fluorite structure at high temperature. Within these systems, there have been numerous studies of the phase transformation from pyrochlore to defect fluorite as a function of composition using various combinations of electron diffraction, laboratory-based X-ray diffraction, synchrotron X-ray diffraction and spectroscopy, and neutron scattering (e.g., Withers et al., 1991; Whittle et al., 2009; Reid 


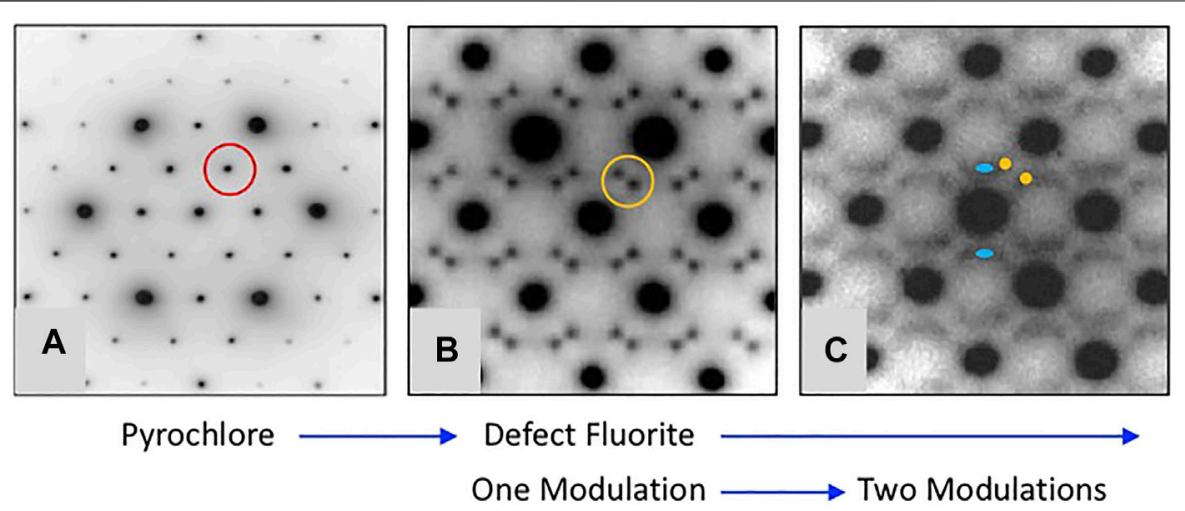

FIGURE 4 | Representative [110] zone axis electron diffraction patterns from $\mathrm{A}_{2} \mathrm{~B}_{2} \mathrm{O}_{7}$ compounds with $\mathrm{A}=\mathrm{Y}$ and $\mathrm{B}=\mathrm{Sn}$ and $\mathrm{Zr}$ showing the development of modulated structures with increasing substitution of Zr for Sn. Figure is modified from De los Reyes et al. (2013). The single modulation in (B) occurs at a moderate level of substitution of $Z r$ for $S n$ and the characteristic split pair is defined as $\left.G_{F} \pm 1 / 2<111\right\rangle^{*}$, e.g., compare the scattering inside the red circle in (A) with that inside of the orange circle in (B). Upon further substitution of Zr for Sn the scattering becomes more complex as shown by diffuse streaks and the appearance of a second modulation defined as $\left.G_{F} \pm 1 / 4<220\right\rangle^{*}$ and marked by the blue ovals in (C). This sequence of diffraction patterns illustrates a common trend in the pyrochlore to defect-fluorite transformation as a function of $r_{A} / r_{B}$ in the various chemical systems.

et al., 2012; Reynolds et al., 2013; Shamblin et al., 2016; Shamblin et al., 2018; Drey et al., 2020). The composition driven phase transformation generally proceeds as a function of the A/B cation ionic radius ratio (e.g., as $r_{A} / r_{B}$ decreases) from $P y$ to $(P y+D F)$ to DF. It is well documented in the literature that the DF phase exhibits modulations of the structure as revealed by electron diffraction. An example of this effect is presented in Figure 4 for the $\mathrm{Y}_{2} \mathrm{Zr}_{\mathrm{x}} \mathrm{Sn}_{2-\mathrm{x}} \mathrm{O}_{7}$ series of compounds (De los Reyes et al., 2013). $\mathrm{W}$ ith increasing $\mathrm{Zr}$ content in this series, the structure transforms from pyrochlore to defect fluorite via a narrow two-phase field, initially showing one modulation $\left(G_{F} \pm 1 / 2<111>^{*}\right)$ of the DF phase which appears as a pair of sharp satellite reflections. With increasing substitution of $\mathrm{Zr}$ for $\mathrm{Sn}$, this modulation becomes diffuse and a second modulation appears $\left(G_{F} \pm 1 / 4<220>^{*}\right)$. This appears to be a characteristic feature of Py-DF solid solutions approaching the C-type rare earth oxide stability field. Using the same series of compounds, Zhang et al. (2013) used a combination of synchrotron X-ray diffraction, X-ray absorption spectroscopy, and $a b$ initio computer simulations to show that a distinct phase transition from ordered pyrochlore to disordered defect-fluorite occurs at $x \sim 1.0-1.2$. However, X-ray absorption near-edge structure (XANES) data for the $\mathrm{Zr} \mathrm{L}_{3}$ and $\mathrm{Y} \mathrm{L}_{2}$-edges demonstrated a gradual evolution of the structure over the entire compositional range. Therefore, it is apparent that the local disorder begins long before the pyrochlore to defect-fluorite phase boundary is reached and continues to develop throughout the defect-fluorite region.

For comparison, Figure 3 also shows a similar structure map for the 215 type compounds based on the same set of A and B-site cations. The knowledge base for compounds with this stoichiometry has been developed only for the compositions with $\mathrm{B}=\mathrm{Ti}$ and, to a lesser extent $\mathrm{B}=\mathrm{Zr}$, with a few additional data points for $B=S n$. Excluding the effects of cooling rate and pressure, the information presented here is reasonably complete for samples with $\mathrm{B}=\mathrm{Ti}$. The available data show that the $\mathrm{A}_{2} \mathrm{TiO}_{5}$ compounds are orthorhombic for

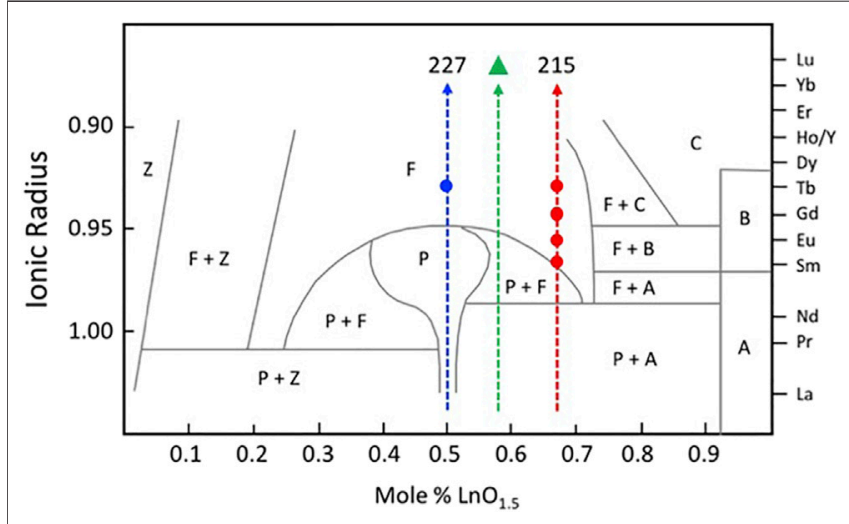

FIGURE 5| Phase fields found in the $\mathrm{ZrO}_{2}-\mathrm{Ln}_{2} \mathrm{O}_{3}$ system. This figure is adapted from Tabira et al. (2001). $\mathrm{Z}=\mathrm{ZrO}_{2}, \mathrm{~F}=$ defect fluorite, $\mathrm{P}=$ pyrochlore, $\mathrm{A}$ = hexagonal A-type $\mathrm{Ln}_{2} \mathrm{O}_{3}, \mathrm{~B}=$ monoclinic $\mathrm{B}$-type $\mathrm{Ln}_{2} \mathrm{O}_{3}$, and $\mathrm{C}=\mathrm{C}$-type $\mathrm{Ln}_{2} \mathrm{O}_{3}$ (cubic bixbyite structure). The vertical dashed lines mark the stoichiometries of the 227, delta phase (green triangle), and 215 compounds in this system. The solid blue circle shows the location of the $\mathrm{Tb}_{2} \mathrm{Zr}_{2} \mathrm{O}_{7}$ defect fluorite phase. The solid red circles show the locations of the $\mathrm{Sm}_{2} \mathrm{ZrO}_{5}$, $\mathrm{Eu}_{2} \mathrm{ZrO}_{5}, \mathrm{Gd}_{2} \mathrm{ZrO}_{5}$, and $\mathrm{Tb}_{2} \mathrm{ZrO}_{5}$ defect fluorite phases (see Figures 6, 7 for a discussion of the diffuse scattering features in these compounds resulting from modulations of the parent defect fluorite structure).

$\mathrm{A}=\mathrm{La}-\mathrm{Sm}$; orthorhombic or hexagonal for $\mathrm{A}=\mathrm{Eu}$ and $\mathrm{Gd}$; orthorhombic, hexagonal, or cubic (defect fluorite) for $\mathrm{Tb}$ and Dy; tripled pyrochlore for Ho and Y; and defect fluorite structures for Er-Lu. For these compounds, the phase diagram of Petrova et al. (1982) is the current benchmark for the high temperature behaviour. The topology of this phase diagram is the basis for much of the recent work in providing a detailed description of phase fields as a function of composition and temperature. The phase diagram shows that the melting points of the various compounds increase from about 1,600 to $2,200^{\circ} \mathrm{C}$ with decreasing ionic radius from $\mathrm{La}$ through to $\mathrm{Yb}$. The topology of the phase diagram indicates that the solid-state phase 


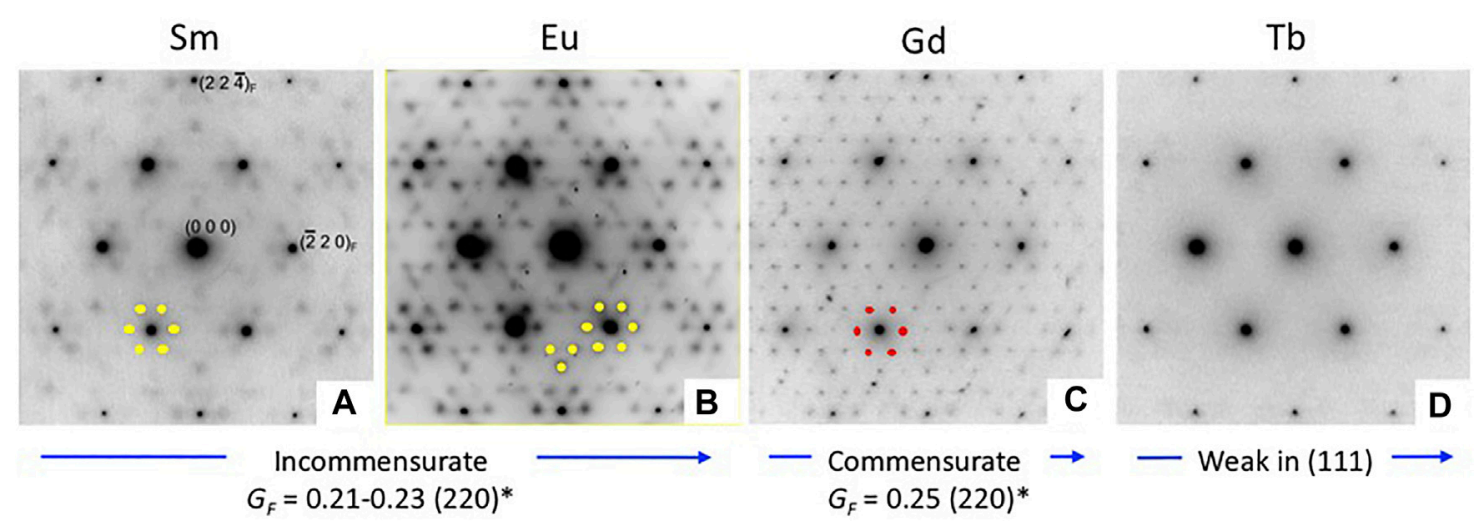

FIGURE 6 | Electron diffraction patterns taken for the [111] zone axis for $\mathrm{Sm}_{2} \mathrm{ZrO}_{5}$ (A), Eu $\mathrm{ZrO}_{5}$ (B), $\mathrm{Gd}_{2} \mathrm{ZrO}_{5}$ (C), and $\mathrm{Tb}_{2} \mathrm{ZrO}_{5}$ (D), showing the gradual changes in the additional scattering features in these compounds with decreasing A-site cation radius from left to right. Modulations of the underlying defect fluorite structure are indicated by the weak beams surrounding the strong ones. Note the gradual change in the modulation of (220) ${ }^{\star}$ and symmetry related beams from $\mathrm{Sm}$ to Tb. Does the (apparently) commensurate (4x) structure in $\mathrm{Gd}_{2} \mathrm{ZrO}_{5}$ indicate ordering in the (111) plane? Note also that the extra diffraction spots are nearly absent in $\mathrm{Tb}_{2} \mathrm{ZrO} \mathrm{Z}_{5}$.

transitions with increasing temperature are likely to proceed from orthorhombic to hexagonal to cubic within a narrow range of ionic radii of the trivalent lanthanide cations, e.g., approximately in the region from Sm to Er. To date, only a few other 215-type compounds have been synthesized with other B-site cations, including samples with $\mathrm{B}=\mathrm{Sn}$, Hf, and mainly $\mathrm{Zr}$. The compounds shown in Figure 3 with $\mathrm{B}=\mathrm{Zr}$ and $\mathrm{A}=\mathrm{Sm}-\mathrm{Yb}$, together with $\mathrm{Sm}_{2} \mathrm{HfO}_{5}$ and $\mathrm{Gd}_{2} \mathrm{HfO}_{5}$, are single-phase defect fluorites, whereas a production run with $\mathrm{A}=\mathrm{La}$ was not stoichiometric, having led to the formation of A-type $\mathrm{La}_{2} \mathrm{O}_{3}$ as a second phase. Other samples produced with $\mathrm{B}=\mathrm{Sn}$ also contained a second phase, either A-type or B-type sesquioxide depending on the particular lanthanide cation on the A-site. Microanalysis of the run product for $\mathrm{Y}_{2} \mathrm{SnO}_{5}$ indicated that it had both A-site vacancies and C-type $\mathrm{Y}_{2} \mathrm{O}_{3}$ as a second phase (see Newman et al., 2018).

A considerable amount of additional information related to the "stability" fields of defect fluorite, pyrochlore, and their component oxides is available in the phase diagram (or structure-field map) presented by Tabira et al. (2001), reproduced here in slightly modified form in Figure 5. This figure was developed specifically for the $\mathrm{Ln}_{2} \mathrm{O}_{3}-\mathrm{ZrO}_{2}$ system of compounds and shows the various single phase and two-phase fields as a function of the $\mathrm{LnO}_{1.5}$ content (mole \%) on the $x$-axis versus the ionic radii of the $\operatorname{Ln}$ cations on the $y$-axis. This particular diagram provides an excellent basis for understanding the nature of the defect fluorite phase and the types of modulations that occur as a function of composition in the single-phase region and in two-phase regions next to the phase field of zirconia, on either side of the pyrochlore field, and next to the phase fields of the A, B, and C-type rare earth oxides. This work helped to underpin the concept of a Py to DF transformation driven by strain in the close-packed $\{111\}$ cation layers of the DF structure by cation and oxygen vacancies. In Figure 5, we also plot the locations of four 215type compounds with $\mathrm{A}=\mathrm{Sm}, \mathrm{Eu}, \mathrm{Gd}$, and $\mathrm{Tb}$ (red dots). The structural complexity of these compounds is illustrated in
Figure 6, showing the gradual evolution of the modulations in their [111] zone axis electron diffraction patterns. With decreasing ionic radius of the A-site cation, these compositions transition away from the pyrochlore + fluorite two-phase field and presumably toward the fluorite + C-type $\mathrm{Ln}_{2} \mathrm{O}_{3}$ field. On proceeding from $\mathrm{A}=\mathrm{Sm}$ through to $\mathrm{Tb}$, the modulations become stronger and transition from incommensurate to (apparently) commensurate for $A=G d$, but they are very weak and diffuse for $\mathrm{A}=\mathrm{Tb}$. Finally, we note also that the structural modulations for $\mathrm{Tb}_{2} \mathrm{Zr}_{2} \mathrm{O}_{7}$ and $\mathrm{Tb}_{2} \mathrm{ZrO}_{5}$ in the [110] zone axis are virtually identical, indicating that the stoichiometry change from 227 to 215 type has not changed the modulation wave vector significantly (Figure 7). This is another interesting problem for the detailed interpretation of strain-driven transformations in this system as a function of the $\mathrm{Tb} / \mathrm{Zr}$ ratio.

\section{RADIATION TOLERANCE}

The radiation tolerance of the large group of fluorite and related compounds has been studied extensively for the $\mathrm{MX}_{2}$ fluorite compounds and the $\mathrm{A}_{2} \mathrm{~B}_{2} \mathrm{O}_{7}$ pyrochlore and defect fluorite compounds. Furthermore, there is a growing body of evidence in relation to the radiation tolerance and other properties of the $\mathrm{A}_{2} \mathrm{BO}_{5}$ compounds. This will be discussed briefly here for several different experimental methods. Atomistic simulations investigate the performance of the material on picosecond time scales through an analysis of the energetics of defect formation and migration (e.g., Minervini et al., 2000; Jiang et al., 2009). In the latter context, one may generally consider that radiation tolerance is promoted by high defect formation energies and low energy barriers to atomic migration in the host structure. In this situation, it is more difficult to move an atom out of its normal crystallographic site, but if enough energy is imparted to the atom to displace it, then it may easily return to either the original site or a similar one nearby. On the other 


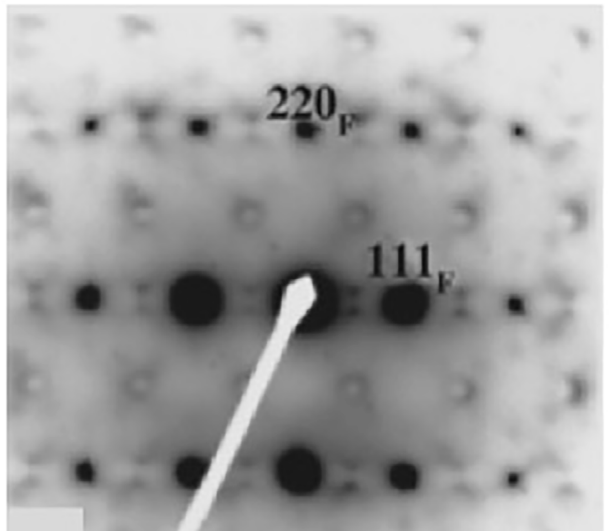

A

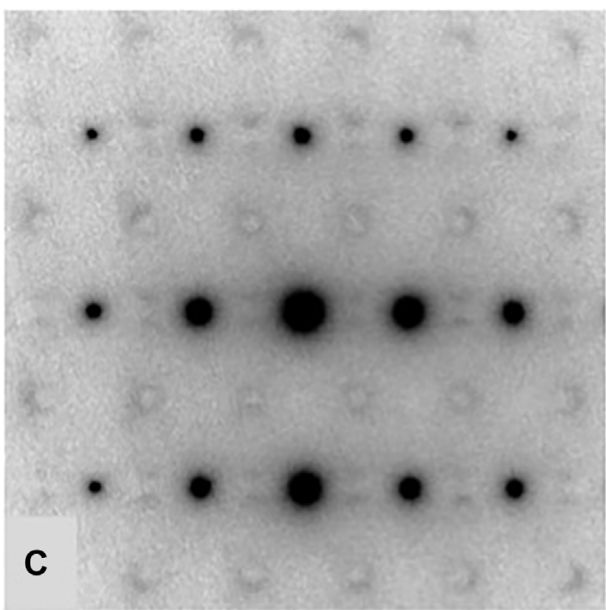

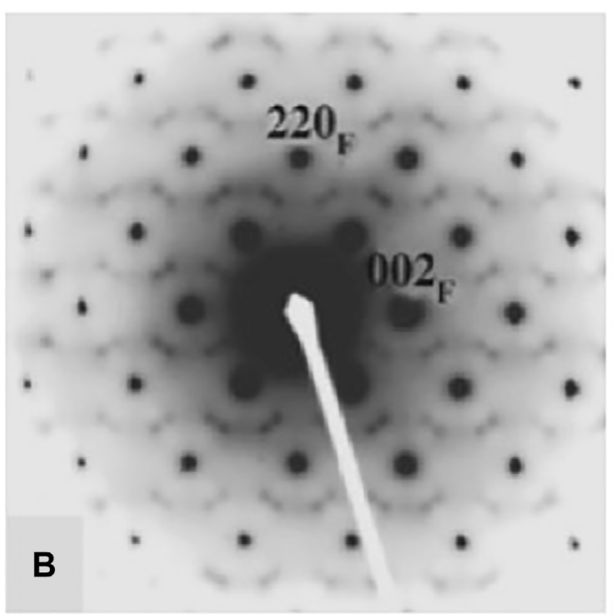

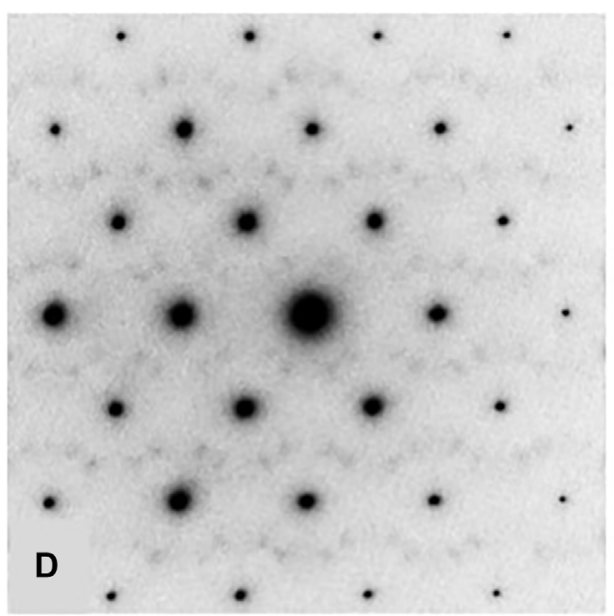

FIGURE 7 | Comparison of diffuse scattering features in $\mathrm{Tb}_{2} \mathrm{Zr}_{2} \mathrm{O}_{7}$ (A,B) and $\mathrm{Tb}_{2} \mathrm{ZrO}_{5}$ (C,D). Both compounds are defect fluorite structure types showing characteristic modulations the [112] zone axis in (A,C) and the [011] zone axis in (B,D). However, in spite of the major difference in composition (A/B cation ratio and number of anion vacancies), the diffuse features and their measured wave vectors are identical within error. Figures (A,B) are after Tabira et al. (2001).

hand, if energy barriers to migration are high, it is more likely that radiation-induced displacements and damage will be retained under a given set of conditions (time, temperature, etc.). These principles have been demonstrated by a combination of theoretical and experimental work over the course of 30 years or more. A major outcome of the modelling work on compounds with $\mathrm{A}_{2} \mathrm{~B}_{2} \mathrm{O}_{7}$ stoichiometry is that pyrochlore and defect fluorite compounds exhibit lower cation antisite and anion Frenkel defect formation energies as a function of the $\mathrm{A} / \mathrm{B}$ cation radius ratio $\mathrm{r}_{\mathrm{A}} /$ $r_{B}$. As the value of $r_{A} / r_{B}$ decreases, the structures may transform from pyrochlore to a defect fluorite structure as a function of temperature or possibly as a result of radiation damage.

Many ion irradiation experiments have now been completed where the experimental time is on the scale of minutes or hours (e.g., Begg et al., 2001; Aughterson et al., 2016, Aughterson et al., 2018a; Aughterson et al., 2018b; Park et al., 2018; Whittle et al., 2011). These high dose rate experiments have provided much of the fundamental physics knowledge on radiation damage in fluorite and derivative materials as a function of ion mass, energy, and temperature. Major conclusions to be drawn from these studies indicate that the $\mathrm{A}_{2} \mathrm{~B}_{2} \mathrm{O}_{7}$ pyrochlore and defect fluorite compounds are increasingly radiation tolerant (e.g., high critical amorphization dose and low critical amorphization temperature) as a function of the $A / B$ cation radius ratio $\left(r_{A} /\right.$ $r_{B}$ ). Because the A-sites are devoted to a given set of nuclear waste elements, the B-sites are generally available to host larger cations like $\mathrm{Hf}$ and/or $\mathrm{Zr}$, which increase the value of $\mathrm{r}_{\mathrm{A}} / \mathrm{r}_{\mathrm{B}}$ over that of similar pyrochlores with $\mathrm{B}=\mathrm{Ti}$ (and also provide the potential to improve both the chemical durability and the resistance to amorphization). As a result, a particular group of defect fluorite compounds, e.g., those with $\mathrm{B}=\mathrm{Zr}$ and $\mathrm{A}=$ smaller lanthanides, tend to remain crystalline under irradiation. In the real world, of course, these materials must include actinides and possibly some fission products and impurity elements and maintain a similar level of radiation resistance and chemical durability for optimum performance under wasteform storage conditions. Although the $\mathrm{A}_{2} \mathrm{BO}_{7}$ compounds with $\mathrm{B}=\mathrm{Ti}$ are not radiation tolerant, the orthorhombic structures do exhibit critical 
amorphization temperatures that are lower than those the corresponding $\mathrm{A}_{2} \mathrm{~B}_{2} \mathrm{O}_{7}$ pyrochlore and defect-fluorite compounds. Additionally, the $\mathrm{A}_{2} \mathrm{BO}_{7}$ type compounds have the higher $\mathrm{A} / \mathrm{B}$ cation radius ratio of $2: 1$, in theory allowing higher waste loadings. Finally, the defect-fluorite $\mathrm{A}_{2} \mathrm{BO}_{7}$ compounds with $\mathrm{B}=\mathrm{Zr}$ may have the potential to provide both higher waste loadings, neutron absorbers for criticality control, and "built-in" radiation tolerance.

Unfortunately, only a few candidate materials have been doped with short-lived actinides such as ${ }^{244} \mathrm{Cm}\left(\mathrm{t}_{1 / 2}=18.1 \mathrm{y}\right)$ or ${ }^{238} \mathrm{Pu}\left(\mathrm{t}_{1 / 2}=87.7\right.$ years) where the experiments generally run for less than 5 years and are highly relevant to the development of nuclear waste forms (e.g., Weber 1998; Strachan et al., 2005, 2008). This work has demonstrated that waste forms based on pyrochlore and/or zirconolite become amorphous with increasing dose with the potential for volume expansion (on the order of 5\%) and cracking, thereby increasing the surface area of the waste form. Finally, there have been a few investigations of natural analogues containing long-lived ${ }^{235} \mathrm{U}$ $\left(\mathrm{t}_{1 / 2}=7.0 \times 10^{8} \mathrm{y}\right),{ }^{238} \mathrm{U}\left(\mathrm{t}_{1 / 2}=4.5 \times 10^{9} \mathrm{y}\right)$, and ${ }^{232} \mathrm{Th}\left(\mathrm{t}_{1 / 2}=1.4\right.$ $\times 10^{10} \mathrm{y}$ ), including pyrochlore, zirconolite, and other radioactive minerals. These studies demonstrate that pyrochlore and zirconolite become amorphous with increasing alpha-decay dose. However, it appears that zirconolite and, to a lesser extent, pyrochlore, are capable of actinide retention in all but the most severe conditions imposed by nature. We note here that there are no Zr-rich natural pyrochlores, as the pressure, temperature, and bulk rock compositions generally dictate that $\mathrm{ZrO}_{2}$ (baddeleyite) is a stable phase in the mineral assemblages with low $a\left(\mathrm{SiO}_{2}\right)$, whereas zircon is stable in assemblages with high $a\left(\mathrm{SiO}_{2}\right)$.

Finally, we note here that the radiation damage effects and physical/mechanical properties of natural pyrochlores have recently been studied in some detail in relation to percolation theory, although the compositions of these samples differ significantly from the target compositions of pyrochlore-based nuclear waste forms (e.g., the natural samples may have significant amounts of $\mathrm{Na}$ on the $\mathrm{A}$-site, $\mathrm{Nb}$ and $\mathrm{Ta}$ on the $\mathrm{B}$-site, together with $\mathrm{F}$ and $\mathrm{OH}$ on the $\mathrm{Y}$-site). Nevertheless, the results are significant in providing a fundamental basis for understanding the physical properties of pyrochlore based materials under irradiation. Firstly, Zeitlow et al. (2017) presented a new study of the thermal annealing behaviour and mechanical properties of natural pyrochlore samples with amorphous fractions ranging from about 8 to $100 \%$, showing how the recovery steps of the three most damaged samples systematically increase in temperature as a function of the initial damage fraction. This work included detailed analyses of the Raman and infrared spectra of these samples. Furthermore, Reissner et al. (2020) provided additional of evolution of the hardness and elastic moduli of three of the same samples as a function of the annealing temperature and time (16 h in air, per temperature step). A further assessment of the mechanical behaviour of the pyrochlores was conducted by Beirau and Huber (2021) by using finite element-voxel models the calculate the elastic moduli and hardness values as a function of alpha-decay dose and annealing temperature. It is noteworthy that the implied, model dependent percolation points at $\sim 16 \%$ (p1) and $84 \%$ (p2) of the amorphous fraction are reasonably consistent with previous experimental work on radiation damaged pyrochlores (Lumpkin and Ewing, 1988).

\section{OPPORTUNITY SPACE AND QUESTIONS}

Based on this brief look at defect fluorite and related compounds and systems, it is apparent that there remain considerable opportunities for ongoing research and development within the very large composition space indicated by Table 1. Future research opportunities include the fundamental physical chemistry of phase transitions from the various ordered structure types listed here to their disordered defect fluorite structures or from one ordered structure to another. Knowledge generated from an understanding of the basic crystal chemistry and physical chemistry across these systems opens the door to novel materials research and development, in this case, there are many potential applications in areas such as the high-technology sector and energy/nuclear materials that might benefit from further fundamental research. For these and other applications, future work might be devoted to the development of specialist materials taking advantage of the properties of structure types such as defect fluorite, pyrochlore, weberite, delta phase, and 215-type compounds in the design, production, and testing of new materials. In particular, one area of interest may be the design and testing of composite materials using various combinations of these structure types, provided that phase compatibility can be achieved via both chemical and dimensional compatibility.

In particular, Figure 3 indicates that there are considerable opportunities for research to be conducted within the composition space for the $\mathrm{A}_{2} \mathrm{BO}_{5}$ compounds. Currently, most investigations have focused on the compounds with $\mathrm{B}=\mathrm{Ti}$, with more recent efforts devoted to the materials with $\mathrm{B}=\mathrm{Zr}$ and, to a lesser extent with $B=S n$ and Hf. However, there have been few, if any, investigations into the systems with $\mathrm{B}=\mathrm{Mo}$, Os, Ir, Ru, and $\mathrm{V}$ for this particular stoichiometry. Even in the structures with $\mathrm{B}$ $=\mathrm{Ti}$, there remain some uncertainties in the structures, e.g., as suggested by electron diffraction patterns that might lead to questions about the actual symmetry or in the details related to incommensurate, modulation effects and their origins. The fundamental physical chemistry of new materials with $B=V, R u$, $\mathrm{Rh}, \mathrm{Ir}, \mathrm{Os}$, and Mo (and possibly other elements, e.g., $\mathrm{Sb}, \mathrm{Nb}, \mathrm{Ta}$, and $\mathrm{Pb}$ and $\mathrm{Bi}$ in their different valence states) together with new investigations of samples with $\mathrm{B}=\mathrm{Sn}, \mathrm{Hf}$, and $\mathrm{Zr}$. How do the orthorhombic, hexagonal, cubic, and other structures (e.g., Shepelev and Petrova, 2006, Shepelev and Petrova, 2008) evolve in these systems as a function of composition and what are their properties? Furthermore, there is considerable scope for new studies to be conducted on the high temperature behavior in the system with $\mathrm{B}=\mathrm{Ti}$ plus variable amounts of other small cations in a substitutional role.

Another opportunity space will involve the future study of structural evolution between the $\mathrm{A}_{2} \mathrm{~B}_{2} \mathrm{O}_{7}$ compounds and their $\mathrm{A}_{2} \mathrm{BO}_{5}$ counterparts. Similar comments apply more broadly to 
some of the other structure types where we may find a wealth of new information (and new functional materials?) in the study of phase transitions between the various delta phase, 215-type, 227type, and 317-type compounds listed in Table 1. An interesting aspect of this problem is the wide variation in composition and stoichiometry $(\mathrm{M} / \mathrm{X}=0.5-0.6$ and $\mathrm{X}$ vacancies $=0.0$ to 0.5 per $\mathrm{M}$ cation) found in the different groups of compounds. Furthermore, the observation in this paper that $\mathrm{Tb}_{2} \mathrm{Zr}_{2} \mathrm{O}_{7}$ and $\mathrm{Tb}_{2} \mathrm{ZrO}_{5}$ exhibit identical modulations of the underlying defect fluorite structure suggests that such modulations are not a precise function of the $\mathrm{Tb} / \mathrm{Zr}$ ratio, $\mathrm{M} / \mathrm{X}$ ratio, or the number of oxygen vacancies $(0.250$ and 0.333$)$, respectively, relative to the disordered $\mathrm{MX}_{2-\mathrm{x}}$ fluorite basis. In general terms, the origin and significance of these unusual crystallographic features presents another interesting topic for future experimental and theoretical work. For example, just what is the fraction of atoms involved in both displacive and compositional components of the modulations and how is this related to the populations of defects discussed below?

Following from the above discussion of modulations, it is of utmost importance to understand the defect chemistry of the fluorite structure and its more complex derivative compounds in greater detail in order to complement studies of physicalchemical properties and radiation damage effects. In ordered pyrochlore, for example, these defects are generally understood to be a combination of cation anti-site (CA) defects, cation Frenkel (CF) defects, and anion Frenkel (AF) defects. The transition from pyrochlore to defect fluorite is related to the energetics of the CA and AF defects and has been mapped out in some detail using atomistic simulations (e.g., Minervini et al., 2000; Jiang et al., 2009; Uberuaga et al., 2015; Archer et al., 2021) as a guide to predict order-disorder trends in these compounds as a function of the ionic radii of the $\mathrm{A}$ and $\mathrm{B}$ cations. In general, the defect formation energies of $\mathrm{CA}$ and $\mathrm{AF}$ defects decrease as the ionic radius ratio $\mathrm{r}_{\mathrm{A}} / \mathrm{r}_{\mathrm{B}}$ decreases and this in turn corresponds to the transformation from pyrochlore to defect fluorite structures in numerous solid solutions. Together with fundamental crystal chemistry parameters, the simulations noted here were also used to develop a predictive model of radiation tolerance in pyrochlore and defect fluorite compounds (Lumpkin et al., 2007). In general terms, it would be very interesting to compare the radiation damage data for $\mathrm{A}_{2} \mathrm{~B}_{2} \mathrm{O}_{7}$ and the cubic $\mathrm{A}_{2} \mathrm{BO}_{5}$ compounds with the same $\mathrm{A}$ and $\mathrm{B}$ cations to explore the effect of anions vacancies on damage recovery, if any. Finally, we suggest that considerable improvements might be made in the study of defects in these compounds through a combined modelling and experimental approach directed toward an

\section{REFERENCES}

Archer, A., Foxhall, H. R., Allan, N. L., Shearer, J. R. W., Gunn, D. S. D., Harding, J. H., et al. (2021). Multiple cascade Radiation Damage Simulations of Pyrochlore. Mol. Simulation 47, 273-283. doi:10.1080/08927022.2020.1805449 Aughterson, R. D., Lumpkin, G. R., de los Reyes, M., Sharma, N., Ling, C. D., Gault, B., et al. (2014). Crystal Structures of Orthorhombic, Hexagonal, and Cubic advanced interpretation of, for example, neutron pair distribution functions with and without specific defects. Furthermore, can the effects of incommensurate structures or layer stacking disorder be incorporated into this problem in a quantitative way? This approach would necessarily involve the calculation of the relevant scattering functions for different structure types with and without an array of defects such as interstitials, vacancies, cation anti-site arrangements, Frenkel defects, and stacking disorder within the host crystal.

\section{AUTHOR CONTRIBUTIONS}

This paper is based on a collection of data from the authors and other information from selected previous publications involving the authors, together with existing information in the literature. GL supervised some of the previous work, including the $\mathrm{PhD}$ research of RA, which forms the basis of part of this paper. GL also supervised some of the work of RA during a previous leadership role and provided the concept for this paper, wrote the first version of the text prior to co-author contributions and review. GL also performed some of the TEM investigations presented here. RA provided the specific scientific leadership and development of concepts and methods that underpinned our research projects, including crystal structure refinements, crystal chemical relationships, and ion irradiation experiments, and drafted Figure 1.

\section{FUNDING}

This work was fully funded and approved by the Australian Nuclear Science and Technology Organisation for publication.

\section{ACKNOWLEDGMENTS}

We thank the staff of the Nuclear Materials Development and Characterisation (NMDC) Platform at ANSTO for providing access to and maintenance of facilities used by the authors. We are greatly indebted to all of our colleagues with whom we have worked closely on the general topics and some of the focused research problems on pyrochlores, defect fluorites, and related compounds and materials over the course of several decades. The authors acknowledge the financial support from the Australian Government under SIA grant SHCC000002.

Compounds of the $\mathrm{Sm}_{(\mathrm{x})} \mathrm{Yb}_{(2-\mathrm{x})} \mathrm{TiO}_{5}$ Series. J. Solid State. Chem. 213, 60-67. doi:10.1016/j.jssc.2014.02.029

Aughterson, R. D., Lumpkin, G. R., Thorogood, G. J., Zhang, Z., Gault, B., and Cairney, J. M. (2015). Crystal Chemistry of the Orthorhombic $L n_{2} \mathrm{TiO}_{5}$ Compounds with $\mathrm{Ln}=\mathrm{La}, \mathrm{Pr}, \mathrm{Nd}, \mathrm{Sm}, \mathrm{Gd}, \mathrm{Tb}$ and Dy. J. Solid State. Chem. 227, 182-192. doi:10.1016/j.jssc.2015.03.003

Aughterson, R. D., Lumpkin, G. R., de los Reyes, M., Gault, B., Baldo, P., Ryan, E., et al. (2016). The Influence of crystal Structure on Ion-Irradiation Tolerance in 
the $\operatorname{Sm}(\mathrm{x}) \mathrm{Yb}(2-\mathrm{x}) \mathrm{TiO} 5$ Series. J. Nucl. Mater. 471, 17-24. doi:10.1016/ j.jnucmat.2015.12.036

Aughterson, R. D., Lumpkin, G. R., Smith, K. L., Reyes, M. d. 1., Davis, J., Avdeev, M., et al. (2018a). The Ion-Irradiation Tolerance of the Pyrochlore to Fluorite $\mathrm{Ho}(\mathrm{x}) \mathrm{Yb}(2-\mathrm{x}) \mathrm{TiO} 5$ and Er2TiO5 Compounds: A TEM Comparative Study Using Both In-Situ and Bulk Ex-Situ Irradiation Approaches. J. Nucl. Mater. 507, 316-326. doi:10.1016/j.jnucmat.2018.05.026

Aughterson, R. D., Lumpkin, G. R., Smith, K. L., Zhang, Z., Sharma, N., and Cairney, J. M. (2018b). The crystal Structures and Corresponding IonIrradiation Response for the $\mathrm{Tb}(\mathrm{x}) \mathrm{Yb}(2-\mathrm{x}) \mathrm{TiO} 5$ Series. Ceramics Int. 44 (1), 511-519. doi:10.1016/j.ceramint.2017.09.205

Bansal, N. P., and Zhu, D. (2007). Effects of Doping on thermal Conductivity of Pyrochlore Oxides for Advanced thermal Barrier Coatings. Mater. Sci. Eng. A 459, 192-195. doi:10.1016/j.msea.2007.01.069

Begg, B. D., Hess, N. J., McCready, D. E., Thevuthasan, S., and Weber, W. J. (2001). Heavy-ion Irradiation Effects in Gd2(Ti2-xZrx)O7 Pyrochlores. J. Nucl. Mater. 289, 188-193. doi:10.1016/s0022-3115(00)00696-6

Beirau, T., and Huber, N. (2021). Percolation Transitions in Pyrochlore: RadiationDamage and Thermally Induced Structural Reorganization. Appl. Phys. Lett. 119, 131905. doi:10.1063/5.0068685

Cai, L., and Nino, J. C. (2009). Complex Ceramic Structures. I. Weberites. Acta Crystallogr. Sect. B 65, 269-290. doi:10.1107/s0108768109011355

Chakoumakos, B. C. (1984). Systematics of the Pyrochlore Structure Type, Ideal $A_{2} B_{2} X_{6} Y$. J. Solid State. Chem. 53, 120-129.

De los Reyes, M., Whittle, K. R., Zhang, Z., Ashbrook, S. E., Mitchell, M. R., Jang, L.-Y., et al. (2013). The Pyrochlore to Defect Fluorite Phase Transition in Y2Sn2-xZrxO7. RSC Adv. 3, 5090-5099. doi:10.1039/c3ra22704a

Drey, D. L., O’Quinn, E. C., Subramani, T., Lilova, K., Baldinozzi, G., Gussev, I. M., et al. (2020). Disorder in Ho2Ti2-xZrxO7: Pyrochlore to Defect Fluorite Solid Solution Series. RSC Adv. 10, 34632-34650. doi:10.1039/d0ra07118h

Euchner, H., Clemens, O., and Reddy, M. A. (2019). Unlocking the Potential of Weberite-type Metal Fluorides in Electrochemical Energy Storage. Npj Comput. Mater. 5, 31. doi:10.1038/s41524-019-0166-3

Gussev, I. M., O’Quinn, E. C., Baldinozzi, G., Neuefeind, J., Ewing, R. C., Zhang, F., et al. (2020). Local Order of Orthorhombic Weberite-type Y3TaO7 as Determined by Neutron Total Scattering and Density Functional Theory Calculationsts. Acta Mater. 196, 704-709. doi:10.1016/j.actamat.2020.07.005

Harvey, E. R., Whittle, K. R., Lumpkin, G. R., Smith, R. I., and Redfern, S. A. T. (2004). Structural Phase Transitions and Solid Solubilities of $(\mathrm{Nd}, \mathrm{La})_{2}(\mathrm{Zr}, \mathrm{Ti})_{2} \mathrm{O}_{7}$ Phases Deduced by Neutron Diffraction. J. Solid State. Chem. 178, 800-810. doi:10.1016/j.jssc.2004.12.030

Icenhower, J. P., Strachan, D. M., Mcgrail, B. P., Scheele, R. D., Rodriguez, E. A., Steele, J. L., et al. (2006). Dissolution Kinetics of Pyrochlore Ceramics for the Disposition of Plutonium. Am. Mineral. 91, 39-53. doi:10.2138/am.2006.1709

Jiang, C., Stanek, C. R., Sickafus, K. E., and Uberuaga, B. P. (2009). First-principles Prediction of Disordering Tendencies in Pyrochlore Oxides. Phys. Rev. B 79, 104203. doi:10.1103/physrevb.79.104203

Knop, O., Cameron, T. S., and Jochem, K. (1982). What Is the True Space Group of Weberite? J. Solid State. Chem. 43, 213-221. doi:10.1016/0022-4596(82)90231-6

Kutty, K. V. G., Rajagopalan, S., Mathews, C. K., and Varadaraju, U. V. (1994). Thermal Expansion Behaviour of Some Rare Earth Oxide Pyrochlores. Mater. Res. Bull. 29, 759-766. doi:10.1016/0025-5408(94)90201-1

Lau, G. C., Ueland, B. G., Dahlberg, M. L., Freitas, R. S., Huang, Q., Zandbergen, H. W., et al. (2007). Structural Disorder and Properties of the Stuffed Pyrochlore $\mathrm{Ho}_{2} \mathrm{TiO}_{5}$. Phys. Rev. B 76, 054430. doi:10.1103/physrevb.76.054430

Lau, G. C., McQueen, T. M., Huang, Q., Zandbergen, H. W., and Cava, R. J. (2008). Long- and Short-Range Order in Stuffed Titanate Pyrochlores. J. Solid State Chem. 181, 45-50. doi:10.1016/j.jssc.2007.10.025

Lumpkin, G. R., and Ewing, R. C. (1988). Alpha-decay Damage in Minerals of the Pyrochlore Group. Phys. Chem. Mineral. 16, 2-20. doi:10.1007/bf00201325

Lumpkin, G. R. (2006). Ceramic Waste Forms for Actinides. Elements 2, 365-372. doi:10.2113/gselements.2.6.365

Lumpkin, G. R., Pruneda, M., Rios, S., Smith, K. L., Trachenko, K., Whittle, K. R., et al. (2007). Nature of the Chemical Bond and Prediction of Radiation Tolerance in Pyrochlore and Defect Fluorite Compounds. J. Solid State. Chem. 180, 1512-1518. doi:10.1016/j.jssc.2007.01.028

Lutique, S., Konings, R. J. M., Rondinella, V. V., Somers, J., and Wiss, T. (2003a). The thermal Conductivity of $\mathrm{Nd} 2 \mathrm{Zr} 2 \mathrm{O} 7$ Pyrochlore and the thermal Behaviour of Pyrochlore-Based Inert Matrix Fuel. J. Alloys Compd. 352, 1-5. doi:10.1016/ s0925-8388(02)01113-1

Lutique, S., Staicu, D., Konings, R. J. M., Rondinella, V. V., Somers, J., and Wiss, T. (2003b). Zirconate Pyrochlore as a Transmutation Target: thermal Behaviour and Radiation Resistance against Fission Fragment Impact. J. Nucl. Mater. 319, 59-64. doi:10.1016/s0022-3115(03)00134-x

Lyashenko, L. P., Shcherbakova, L. G., Belov, D. A., Knerel'man, E. I., and Dremova, N. N. (2010). Synthesis and Electrical Properties of Gd2MO5 (M = Zr, Hf). Inorg. Mater. 46, 1341-1347. doi:10.1134/s0020168510120137

Maram, P. S., Ushakov, S. V., Weber, R. J. K., Benmore, C. J., and Navrotsky, A. (2018). Probing Disorder in Pyrochlore Oxides Using In Situ Synchrotron Diffraction from Levitated Solids-A Thermodynamic Perspective. Sci. Rep. 8, 10658-10711. doi:10.1038/s41598-018-28877-x

Minervini, L., Grimes, R. W., and Sickafus, K. E. (2000). Disorder in Pyrochlore Oxides. J. Am. Ceram. Soc. 83, 1873-1878. doi:10.1111/j.11512916.2000.tb01484.x

Newman, R., Aughterson, R. D., and Lumpkin, G. R. (2018). Synthesis and Structure of Novel A2BO5 Compounds Containing A $=\mathrm{Y}, \mathrm{Yb}, \mathrm{Gd}, \mathrm{Sm}$, and $\mathrm{La}$ and $\mathrm{B}=\mathrm{Zr}$, Ti, and Sn. MRS Adv. 3, 1117-1122. doi:10.1557/adv.2018.210

Park, S., Tracy, C. L., Zhang, F., Palomares, R. I., Park, C., Trautmann, C., et al. (2018). Swift-heavy Ion Irradiation Response and Annealing Behavior of A2TiO5 $(\mathrm{A}=\mathrm{Nd}, \mathrm{Gd}$, and $\mathrm{Yb})$. J. Solid State. Chem. 258, 108-116. doi:10.1016/j.jssc.2017.09.028

Petrova, M. A., Novikova, A. S., and Grebenshchikov, R. G. (1982). Polymorphism of Rare Earth Titanates of the Composition $\mathrm{Ln}_{2} \mathrm{TiO}_{5}$. Inorg. Mater. 18, 236.

Radhakrishnan, A. N., Rao, P. P., Linsa, K. S. M., Deepa, M., and Koshy, P. (2011). Influence of Disorder-To-Order Transition on Lattice thermal Expansion and Oxide Ion Conductivity in $(\mathrm{CaxGd} 1-\mathrm{x}) 2(\mathrm{Zr} 1-\mathrm{xMx}) 2 \mathrm{O} 7$ Pyrochlore Solid Solutions. Dalton Trans. 40, 3839-3848. doi:10.1039/c0dt01688h

Reid, D. P., Stennett, M. C., and Hyatt, N. C. (2012). The Fluorite Related Modulated Structures of the $\mathrm{Gd} 2(\mathrm{Zr} 2-\mathrm{xCex}) \mathrm{O} 7$ Solid Solution: An Analogue for Pu Disposition. J. Solid State. Chem. 191, 2-9. doi:10.1016/ j.jssc.2011.12.039

Reissner, C. E., Roddatis, V., Bismayer, U., Schreiber, A., Pöllmann, H., and Beirau, T. (2020). Mechanical and Structural Response of Radiation-Damaged Pyrochlore to thermal Annealing. Materialia 14, 100950. doi:10.1016/ j.mtla.2020.100950

Reynolds, E., Blanchard, P. E. R., Kennedy, B. J., Ling, C. D., Liu, S., Avdeev, M., et al. (2013). Anion Disorder in Lanthanoid Zirconates Gd2-xTbxZr2O7. Inorg. Chem. 52, 8409-8415. doi:10.1021/ic4009703

Risovany, V. D., Varlashova, E. E., and Suslov, D. N. (2000). Dysprosium Titanate as an Absorber Material for Control Rods. J. Nucl. Mater. 281 (1), 84-89. doi:10.1016/s0022-3115(00)00129-x

Sattonnay, G., Sellami, N., Thomé, L., Legros, C., Grygiel, C., Monnet, I., et al. (2013). Structural Stability of Nd2Zr2O7 Pyrochlore Ion-Irradiated in a Broad Energy Range. Acta Mater. 61, 6492-6505. doi:10.1016/j.actamat.2013.07.027

Shamblin, J., Feygenson, M., Neuefeind, J., Tracy, C. L., Zhang, F., Finkeldei, S., et al. (2016). Probing Disorder in Isometric Pyrochlore and Related Complex Oxides. Nat. Mater 15, 507-511. doi:10.1038/nmat4581

Shamblin, J., Tracy, C. L., Palomares, R. I., O’Quinn, E. C., Ewing, R. C., Neuefeind, J., et al. (2018). Similar Local Order in Disordered Fluorite and Aperiodic Pyrochlore Structures. Acta Mater. 144, 60-67. doi:10.1016/ j.actamat.2017.10.044

Shepelev, Y. F., and Petrova, M. A. (2008). Crystal Structures of Ln2TiO5 ( $L n=$ Gd, Dy) Polymorphs. Inorg. Mater. 44, 1354-1361. doi:10.1134/ s0020168508120170

Shepelev, Y. F., and Petrova, M. A. (2006). Structures of Two High-Temperature Dy2TiO5 Modifications. Russ. J. Inorg. Chem. 51, 1636-1640. doi:10.1134/ s0036023606100196

Shimamura, K., Arima, T., Idemitsu, K., and Inagaki, Y. (2007). Thermophysical Properties of Rare-Earth-Stabilized Zirconia and Zirconate Pyrochlores as Surrogates for Actinide-Doped Zirconia. Int. J. Thermophys. 28, 1074-1084. doi:10.1007/s10765-007-0232-9

Shlyakhtina, A. V., Kolbanev, I. V., Knotko, A. V., Boguslavskii, M. V., Stefanovich, S. Y., Karyagina, O. K., et al. (2005). Ionic Conductivity of Ln2 + X Zr2 - X O7 $\mathrm{X} / 2(\mathrm{Ln}=\mathrm{Sm}-\mathrm{Gd})$ Solid Solutions. Inorg. Mater. 41, 854-863. doi:10.1007/ s10789-005-0226-6 
Simeone, D., Thorogood, G. J., Huo, D., Luneville, L., Baldinozzi, G., Petricek, V., et al. (2017). Intricate Disorder in Defect Fluorite/pyrochlore: a concord of Chemistry and Crystallography. Sci. Rep. 7, 3727. doi:10.1038/s41598-01702787-w

Strachan, D. M., Scheele, R. D., Buck, E. C., Icenhower, J. P., Kozelisky, A. E., Sell, R. L., et al. (2005). Radiation Damage Effects in Candidate Titanates for Pu Disposition: Pyrochlore. J. Nucl. Mater. 345, 109-135. doi:10.1016/ j.jnucmat.2005.04.064

Strachan, D. M., Scheele, R. D., Buck, E. C., Kozelisky, A. E., Sell, R. L., Elovich, R. J., et al. (2008). Radiation Damage Effects in Candidate Titanates for $\mathrm{Pu}$ Disposition: Zirconolite. J. Nucl. Mater. 372, 16-31. doi:10.1016/ j.jnucmat.2007.01.278

Subramanian, M. A., Aravamudan, G., and Subba Rao, G. V. (1983). Oxide Pyrochlores - A Review. Prog. Solid State. Chem. 15, 55-143. doi:10.1016/ 0079-6786(83)90001-8

Tabira, Y., Withers, R. L., Barry, J. C., and Elcoro, L. (2001). The Strain-Driven Pyrochlore to "Defect Fluorite" Phase Transition in Rare Earth Sesquioxide Stabilized Cubic Zirconias. J. Solid State. Chem. 159, 121-129. doi:10.1006/ jssc.2001.9139

Uberuaga, B. P., Tang, M., Jiang, C., Valdez, J. A., Smith, R., Wang, Y., et al. (2015). Opposite Correlations between Cation Disordering and Amorphization Resistance in Spinels versus Pyrochlores. Nat. Commun. 6, 8750. doi:10.1038/ncomms9750

van Dijk, M. P., de Vries, K. J., and Burggraaf, A. J. (1983). Oxygen Ion and Mixed Conductivity in Compounds with the Fluorite and Pyrochlore Structure. Solid State Ionics 9-10, 913-919. doi:10.1016/0167-2738(83)90110-8

Vance, E. R., Lumpkin, G. R., Carter, M. L., Cassidy, D. J., Ball, C. J., Day, R. A., et al. (2002). Incorporation of Uranium in Zirconolite $\left(\mathrm{CaZrTi}_{2} \mathrm{O}_{7}\right)$. J. Am. Ceram. Soc. 85 (7), 1853-1859. doi:10.1111/j.1151-2916.2002.tb00364.x

Vassen, R., Cao, X., Tietz, F., Basu, D., and Stöver, D. (2000). Zirconates as New Materials for thermal Barrier Coatings. J. Am. Ceram. Soc. 83, 2023-2028. doi:10.1111/j.1151-2916.2000.tb01506.X

Wang, S. X., Begg, B. D., Wang, L. M., Ewing, R. C., Weber, W. J., and Kutty, K. V. G. (1999). Radiation Stability of Gadolinium Zirconate: A Waste Form for Plutonium Disposition. J. Mater. Res. 14, 4470-4473. doi:10.1557/jmr.1999.0606

Weber, W. J. (1998). Effects of Self-Radiation Damage in Cm-Doped $\mathrm{Gd}_{2} \mathrm{Ti}_{2} \mathrm{O}_{7}$ and $\mathrm{CaZrTi}_{2} \mathrm{O}_{7}$. J. Mater. Res. 13 (6), 1434-1484.

Whittle, K. R., Blackford, M. G., Aughterson, R. D., Lumpkin, G. R., and Zaluzec, N. J. (2011). Ion Irradiation of Novel Yttrium/ytterbium-Based Pyrochlores: The Effect of Disorder. Acta Materialia 59, 7530-7537. doi:10.1016/ j.actamat.2011.09.021
Whittle, K. R., Cranswick, L. M. D., Redfern, S. A. T., Swainson, I. P., and Lumpkin, G. R. (2009). Lanthanum Pyrochlores and the Effect of Yttrium Addition in the Systems La2-xYxZr2O7 and La2-xYxHf2O7. J. Solid State. Chem. 182, 442-450. doi:10.1016/j.jssc.2008.11.008

Withers, R. L., Thompson, J. G., and Barlow, P. J. (1991). An Electron, and X-ray Powder, Diffraction Study of Cubic, Fluorite-Related Phases in Various ZrO2-Ln2O3 Systems. J. Solid State. Chem. 94, 89-105. doi:10.1016/00224596(91)90224-6

Wu, J., Wei, X., Padture, N., Klemens, P. G., Gell, M., García, E., et al. (2002). Lowthermal-conductivity Rare-earth Zirconates for Potential thermal-barriercoating Applications. J. Am. Ceram. Soc. 85, 3031-3035. doi:10.1111/j.11512916.2002.tb00574.x

Zhang, Z., Middleburgh, S. C., de los Reyes, M., Lumpkin, G. R., Kennedy, B. J., Blanchard, P. E. R., et al. (2013). Gradual Structural Evolution from Pyrochlore to Defect-Fluorite in Y2Sn2-xZrxO7: Average vs Local Structure. J. Phys. Chem. C 117, 26740-26749. doi:10.1021/jp408682r

Zhou, L., Huang, Z., Qi, J., Feng, Z., Wu, D., Zhang, W., et al. (2016). Thermaldriven Fluorite-Pyrochlore-Fluorite Phase Transitions of Gd2Zr2O7 Ceramics Probed in Large Range of Sintering Temperature. Metall. Mat Trans. A. 47, 623-630. doi:10.1007/s11661-015-3234-4

Zietlow, P., Beirau, T., Mihailova, B., Groat, L. A., Chudy, T., Shelyug, A., et al. (2017). Thermal Annealing of Natural, Radiation-Damaged Pyrochlore. Z. Kristallograph. 232, 25-38. doi:10.1515/zkri-2016-1965

Conflict of Interest: The authors declare that the research was conducted in the absence of any commercial or financial relationships that could be construed as a potential conflict of interest.

Publisher's Note: All claims expressed in this article are solely those of the authors and do not necessarily represent those of their affiliated organizations, or those of the publisher, the editors and the reviewers. Any product that may be evaluated in this article, or claim that may be made by its manufacturer, is not guaranteed or endorsed by the publisher.

Copyright (c) 2021 Lumpkin and Aughterson. This is an open-access article distributed under the terms of the Creative Commons Attribution License (CC $B Y)$. The use, distribution or reproduction in other forums is permitted, provided the original author(s) and the copyright owner(s) are credited and that the original publication in this journal is cited, in accordance with accepted academic practice. No use, distribution or reproduction is permitted which does not comply with these terms. 